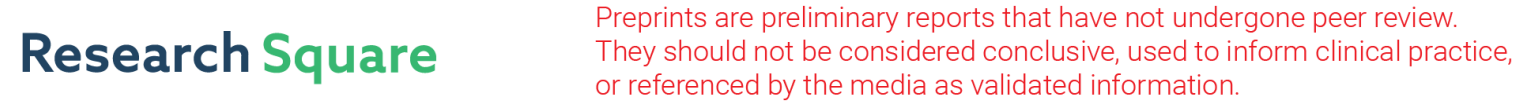 \\ How Effective Is Traffic and Production Restriction for Air Pollution? Evidence From a Quasi-natural Experiment in China
}

\section{Yiqing Chen}

China University of Geosciences

Deyun Wang ( $\square$ wang.deyun@hotmail.com )

China University of Geosciences

Adnen Elamraoui

Universite d'Artois

Haixiang Guo

China University of Geosciences

\section{Research Article}

Keywords: traffic and production restriction, air pollution, COVID-19, Spring Festival effect, structural break points

Posted Date: August 17th, 2021

DOl: https://doi.org/10.21203/rs.3.rs-705406/v1

License: (c) (i) This work is licensed under a Creative Commons Attribution 4.0 International License. Read Full License 


\section{How effective is traffic and production restriction for air pollution? Evidence from a quasi-natural experiment in China}

${ }^{a}$ School of Economics and Management, China University of Geosciences, Wuhan 430074, China

b Univ. Artois, EA 3926, Laboratoire de Génie Informatique et d'Automatique de l'Artois (LGI2A), F-62400 Béthune, France

Abstract: Air pollution seriously affects human health. The traffic and production restriction is widely used for controlling heavy air pollution. However, the effectiveness of these two policies has not been scientifically verified through a city-level study. COVID-19 pandemic caused lockdowns in many cities, which makes it possible to verify the effectiveness of these two policies. Taken Wuhan as the study area, this study firstly verifies the existence of lockdown effect on air pollution and analyzes the evolution rule of six air pollutants ( $\mathrm{PM}_{2.5}, \mathrm{PM}_{10}, \mathrm{NO}_{2}, \mathrm{SO}_{2}, \mathrm{CO}$ and $\left.\mathrm{O}_{3}\right)$ using statistical methods. Then the structural break points in six air pollutants are detected with the regression discontinuity design model. Because Spring Festival overlapping COVID-19 may also affect the air pollution, in order to avoid the disturbance of Spring Festival on the results, the Spring Festival effect is also validated. The results illustrate that the effects of traffic and production restriction on six air pollutants are obviously different, in which the concentrations of $\mathrm{PM}_{2.5}, \mathrm{PM}_{10}$ and $\mathrm{NO}_{2}$ decrease significantly, while traffic and production restriction has no apparent effects on $\mathrm{SO}_{2}, \mathrm{CO}$ and $\mathrm{O}_{3}$. Moreover, the structural break points are verified in the four air pollutants $\left(\mathrm{PM}_{2.5}, \mathrm{PM}_{10}, \mathrm{NO}_{2}\right.$ and $\left.\mathrm{CO}\right)$, and the structural break points are caused by lockdown instead of Spring Festival. This study revealed how the traffic and production restriction affected the air pollution at a city level, and provided strong implementation basis to the air pollution control policy.

Keywords: traffic and production restriction, air pollution, COVID-19, Spring Festival effect, structural break points

\footnotetext{
* Corresponding author. Tel.: +86 2767848527; E-mail address: wangdy@ cug.edu.cn (D. Wang)
} 


\title{
How effective is traffic and production restriction for air pollution? Evidence from a quasi-natural experiment in China
}

\begin{abstract}
Air pollution seriously affects human health. The traffic and production restriction is widely used for controlling heavy air pollution. However, the effectiveness of these two policies has not been scientifically verified through a city-level study. COVID-19 pandemic caused lockdowns in many cities, which makes it possible to verify the effectiveness of these two policies. Taken Wuhan as the study area, this study firstly verifies the existence of lockdown effect on air pollution and analyzes the evolution rule of six air pollutants $\left(\mathrm{PM}_{2.5}, \mathrm{PM}_{10}, \mathrm{NO}_{2}, \mathrm{SO}_{2}, \mathrm{CO}\right.$ and $\left.\mathrm{O}_{3}\right)$ using statistical methods. Then the structural break points in six air pollutants are detected with the regression discontinuity design model. Because Spring Festival overlapping COVID-19 may also affect the air pollution, in order to avoid the disturbance of Spring Festival on the results, the Spring Festival effect is also validated. The results illustrate that the effects of traffic and production restriction on six air pollutants are obviously different, in which the concentrations of $\mathrm{PM}_{2.5}, \mathrm{PM}_{10}$ and $\mathrm{NO}_{2}$ decrease significantly, while traffic and production restriction has no apparent effects on $\mathrm{SO}_{2}, \mathrm{CO}$ and $\mathrm{O}_{3}$. Moreover, the structural break points are verified in the four air pollutants $\left(\mathrm{PM}_{2.5}, \mathrm{PM}_{10}, \mathrm{NO}_{2}\right.$ and $\left.\mathrm{CO}\right)$, and the structural break points are caused by lockdown instead of Spring Festival. This study revealed how the traffic and production restriction affected the air pollution at a city level, and provided strong implementation basis to the air pollution control policy.
\end{abstract}

Keywords: traffic and production restriction, air pollution, COVID-19, Spring Festival effect, structural break points

\section{Introduction}

In the past several decades, the acceleration of urbanization and rapid economy development not only bring enormous benefits to people, but also cause lots of air pollution problems. The correlation between air pollution and many adverse human respiratory and cardiovascular diseases has been verified by previous researches (Danesh Yazdi et al., 2019; Hao et al., 2019; Yu et al., 2020). Lots of cities located in north part of China have suffered from serious air pollution for many years, and many air pollution control policies have been implemented in the past ten years. Some scholars have illustrated that the air pollutants mainly derived from industry and traffic(Alahmad et al., 2021; Choi and Myong, 2018; Miao et al., 2019). Therefore, the production restriction (or suspension) on high-pollution industries such as steel and building material factories and even-odd traffic restriction are often adopted to tackle heavy air pollution incidents. However, these two 
measures are often applied in small area for a short time in order to reduce the negative influences on human activities (De La Cruz et al., 2019; Hua et al., 2021; Tao et al., 2021). Thus, the effectiveness of these two measures have not been scientifically verified through a city-level empirical study, which leads to the lack of implementation basis of these two measures. In many cities all over the world, the COVID-19 pandemic caused long-term and large area lockdowns which was equivalent to a strict environmental regulation, namely the traffic and production restriction or suspension, which makes it possible to verify the effectiveness of these two measures on air pollution control at a city level.

Some researchers have investigated the apparent differences of various air pollutants' concentrations before and after lockdown without considering the different evolution rules of air pollutants in different lockdown periods. Nakada and Urban (2020) compared the concentrations of different air pollutants before and after partial lockdown in Sao Paulo, Brazil, and found that the $\mathrm{NO}, \mathrm{NO}_{2}$ and $\mathrm{CO}$ concentrations decreased significantly. Chauhan and Singh (2020) found a decline in $\mathrm{PM}_{2.5}$ from December 2019 to March 2020 (COVID-19 period) in major cities around the world. Berman and Ebisu (2020) evaluated $\mathrm{PM}_{2.5}$ and $\mathrm{NO}_{2}$ concentrations during the COVID-19 period and the pre-COVID-19 period in the continental United States, the results illustrated remarkable decreases in both $\mathrm{PM}_{2.5}$ and $\mathrm{NO}_{2}$ concentrations. Razzaq et al. (2020) investigated the link between COVID-19 and ozone pollution in the top ten affected states of United States, the results confirmed overall dependence between COVID-19 and ozone pollution. Zangari et al. (2020) examined the air quality changes in New York City based on first 17 weeks' $\mathrm{PM}_{2.5}$ and $\mathrm{NO}_{2}$ concentrations (from January to May) of 2015-2020. Baldasano (2020) investigated the effects of traffic reduction in lockdown on $\mathrm{NO}_{2}$ concentration and found that $\mathrm{NO}_{2}$ concentration decreased 50\% and 62\% in Barcelona and Madrid, respectively. Ali et al. (2021) analyzed the linkage between $\mathrm{PM}_{2.5}$ concentration and COVID-19 spread in four major cities located in Pakistan.

In order to prevent the rapid widespread transmission of COVID-19, the restriction policies related traffic and production are continuously adjusted and consequently have a time-varying influence on the air pollution. Therefore, analyzing the effects of traffic and production restrictions on air pollution within different lockdown periods can obtain more reasonable results. Talbot et al. (2021) firstly separated the lockdown period in New Zealand into three phases and then analyzed the modifications of $\mathrm{PM}_{2.5}, \mathrm{PM}_{10}$ and $\mathrm{NO}_{2}$ concentrations within different phases. Yuan et al. (2021) analyzed the lockdown effect on air pollution in Hangzhou by dividing the lockdown period into five stages and found that the air pollutants' concentrations have remarkable declines in the third phase (COVID-Lock). Li et al. (2020) explored the effect of human activities on air pollution during the lockdown over the Yangtze River Delta region through separating the lockdown period 
into four stages. Zhang et al. (2021) analyzed the modifications of average air pollutants' concentrations in China by splitting the first quarter of 2020 into four stages.

The contribution and novelty of this study is twofold. (1) The strict and rapid lockdown policies which can be mainly regarded as traffic and production restriction may lead to sharp changes in air pollution. Detecting the sharp changes in different air pollutants can help people understand how the lockdown affect different air pollutants. However, few scholars considered the sharp change detection in their studies. The regression discontinuity design (RDD) model is a widely used method to capture this kind of sudden change. Thus, this study validates the sharp changes in different air pollutants during lockdown period utilizing the RDD model, and found that these sharp changes only existed in the $\mathrm{PM}_{2.5}, \mathrm{PM}_{10}, \mathrm{CO}$ and $\mathrm{NO}_{2}$, which indicates that the lockdown only affected $\mathrm{PM}_{2.5}, \mathrm{PM}_{10}, \mathrm{CO}$ and $\mathrm{NO}_{2}$ concentrations instead of $\mathrm{SO}_{2}$ and $\mathrm{O}_{3}$ concentrations. Moreover, with comparison of the RDD coefficient of $\mathrm{PM}_{2.5}(-34.46), \mathrm{PM}_{10}(-37.11)$ and $\mathrm{NO}_{2}$ $(-19.15)$, the coefficient of CO $(-0.32)$ indicates that the traffic and production restriction has less influence on $\mathrm{CO}$ concentration compared to that on $\mathrm{PM}_{2.5}, \mathrm{PM}_{10}, \mathrm{NO}_{2}$ concentrations. (2) In the Spring Festival, a legal holiday in China, most of industries are usually suspended and consequently the air pollution may be influenced in this period. Because the Spring Festival in 2020 overlapped with the COVD-19, ignoring the Spring Festival effect may reduce the reliability of the results. However, the above studies on China have rarely considered the dual effects of Spring Festival and lockdown on air quality. In this study, the Spring Festival effect on the air pollution is investigated based on RDD model through comparing the sharp changes in air pollutants during the Spring Festival in 2019 and 2020, and found that there are no any sharp changes in the air pollutants in 2019, thus we can deduce that the sharp changes in the air pollutants in 2020 are unlikely to be caused by the Spring Festival.

The remainder of this paper is organized as follows. Section 2 introduces the study materials and methods, Section 3 presents the empirical results, Section 4 discusses the implication of the findings, and Section 5 concludes this study.

\section{Materials and methods}

\subsection{Study areas and periods}

This study aims to verify the effects of traffic and production restriction on air pollution, therefore, the city adopted in this study should satisfy the following two conditions: (1) the city often suffered from serious air pollution; (2) traffic and production restriction is implemented widely at a city level for a long enough period of time.

Wuhan, a mega-city in central China, is the capital of Hubei Province and has an area of 
8569.15 square kilometers and a population of 11.21 million. As a typical industrial and resource-based city, Wuhan not only suffered from the typical aerosol particles $\left(\mathrm{PM}_{2.5}, \mathrm{PM}_{10}\right)$ but also the gaseous pollutants $\left(\mathrm{NO}_{\mathrm{x}}, \mathrm{SO}_{2}, \mathrm{O}_{3}, \mathrm{CO}\right.$ ) (Al-Qaness et al., 2020; Sulaymon et al., 2021; Yang et al., 2019). As shown in Fig. 1, in China, Wuhan has suffered from the most severe COVID-19 pandemic which caused the strictest lockdown. Wuhan has experienced the complete process from large scale lockdown to recovery in China. Therefore, the traffic and production restriction which is the main lockdown policy was adequately implemented in Wuhan. Thus, Wuhan satisfies the above two conditions and is consequently suitable for verifying the effects of traffic and production restriction on the air pollution.

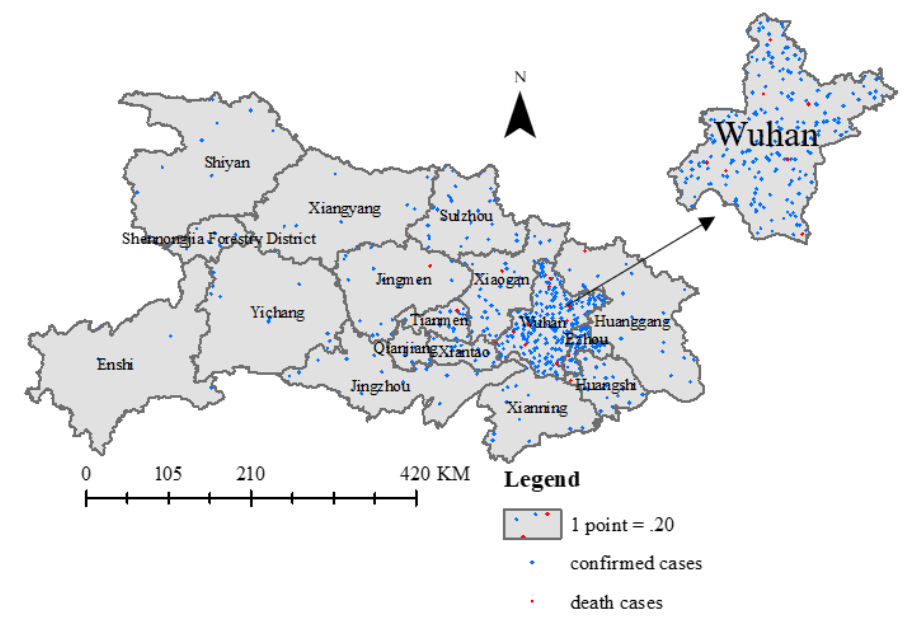

Fig. 1. Density map of the COVID-19 confirmed cases and associated deaths in Hubei, China

With dispersion of COVID-19, different lockdown policies were implemented, and consequently may have different effects on air pollution. Thus, it is vital to find out the implementation dates of different lockdown policies before analyzing the relationship between lockdown and air pollution. After carefully studying the whole process of lockdown in Wuhan, the following four time nodes can be adopted to represent the adjustments of lockdown policies (see Table 1).

Table 1 Time nodes of important events in the lockdown period

\begin{tabular}{ll}
\hline Time nodes & Important events \\
\hline Jan 23rd & The beginning of China's Spring Festival; \\
& The highest public health emergency response was implemented \\
Feb 13th & The end of Spring Festival \\
Mar 20th & Enterprises resumed production \\
Apr 07th & Wuhan officially emerged from lockdown \\
\hline
\end{tabular}


According to the above four time points, the lockdown period can be divided into the following four phases: pre-lockdown (January 1-January 23); level-I lockdown (January 24-February 13); level-II lockdown (February 14-March 20); level-III lockdown (March 21-April 7). Fig. 2 shows the different restrictions on production and traffic in each phase of lockdown. In lockdown, the strictest traffic restriction was enforced on all outbound routes from Wuhan. International passenger flights, ferries and long-distance passenger transport services in Wuhan were all suspended. Airports and railway stations were closed and intra-city public transport halted in Wuhan. Moreover, all of the non-essential enterprises were suspended.

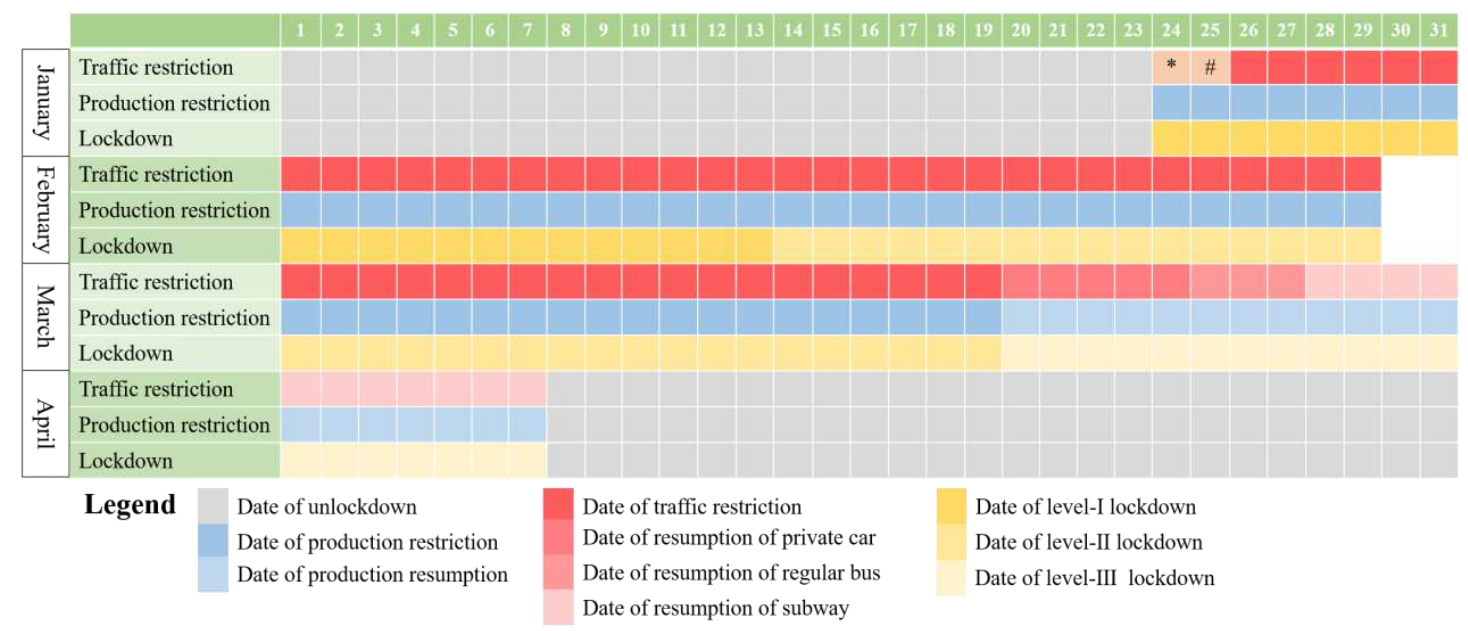

Note: * The online-hailing service was restricted; \# Motor vehicle was banned

Fig. 2. The implementation date of different traffic and production restrictions in lockdown

\subsection{Data sources}

Daily data of $\mathrm{PM}_{2.5}, \mathrm{PM}_{10}, \mathrm{SO}_{2}, \mathrm{CO}, \mathrm{NO}_{2}$ and $\mathrm{O}_{3}$ concentrations from January 1 st to April 7 th, 2020 in Wuhan were collected from China's online air quality monitoring and analysis platform (http://www.aqistudy.cn). In order to evaluate the modification of air pollution in lockdown, the data during the same study period in 2017-2019 were also collected and adopted as the reference data, see Fig. 3.

\subsection{Methods}

\subsubsection{Methods for analyzing air pollution modification}

In this study, the Kruskal-Wallis (K-W) test and Kolmogorov-Smirnov (K-S) test were used to compare the air pollution modifications during the same lockdown period (i.e., January 1st -April 7th) for each of the last four years (2017-2020). Moreover, paired t-test was used to verify the air pollution modifications in pre-lockdown, level-I, level-II, and level-III. These three statistical methods are briefly introduced as follows. 
The K-W test statistics can be calculated as follows if there are no ties (i.e., there are no equivalent observations):

$$
H=\frac{12}{N(N+1)} \sum_{i=1}^{\mathrm{k}} \frac{R_{i+}^{2}}{n_{i}}-3(N+1)
$$

where $\mathrm{k}$ is the number of samples, $n_{i}$ means the size of the $i$ th sample and $i=1,2, \ldots, k$, $N=\sum n_{i}$ is the number of observations in all samples combined, $R_{i+}=n_{i} \overline{R_{i}}=\sum_{j=1}^{n_{i}} R_{i j}$ means the sum of the ranks in the $i$ th sample.

If there are ties, each observation is given the average value of the ranks for which it is tied. $H$ has to be modified so that its expectation is still equal to k-1. After averaging the rank, the revised $H$ statistic can be presented as follows:

$$
H_{a}=\frac{H}{1-\frac{\sum_{t=1}^{g}\left(\tau_{t}^{3}-\tau_{t}\right)}{N^{3}-N}}, H_{a}: \chi^{2}(k-1)
$$

where $g$ is the number of ties in the combined samples $\left\{x_{i 1}, x_{i 2}, \ldots, x_{i i_{i}}, i=1,2, \ldots, k\right\}, \tau_{t}$ means the length of the $i$ th tie, and $t=1,2, \ldots, g$.

(b) Kolmogorov-Smirnov test

We assume that the sample sizes of the two samples are $n_{1}$ and $n_{2} . F_{1}(x)$ and $F_{2}(x)$ are used to represent the cumulative experience functions of the two samples. Let $D_{j}$ equal to $F_{1}\left(X_{j}\right)-F_{2}\left(X_{j}\right)$, and then the K-S statistics can be calculated as follows:

$$
Z=\max _{j}\left|D_{j}\right| \sqrt{\frac{n_{1} n_{2}}{n_{1}+n_{2}}}
$$

(c) Paired t-test

The formula of paired t-test was as follows:

$$
t=\frac{d}{s / \sqrt{n}}
$$

where $\mathrm{d}$ was the mean value of the observed differences, and the noise was described using the standard error, which was calculated by dividing the standard deviation of the difference by the square root of the sample size (n).

\subsubsection{Methods for validation of Structural break points in six air pollutants}

RDD is used to verify the structural break points in six air pollutants. Assuming that before the experiment, the variables $x_{i}$ and $y_{i}$ had a linear relationship: $y_{i}=\alpha+\beta x_{i}+\varepsilon_{i}(i=1, . ., n)$; if the treatment effect for $D_{i}=1\left(x_{i} \geq c\right)$ (constant $\mathrm{c}$ is the breakpoint) is positive, then the linear relationship between $x_{i}$ and $y_{i}$ has a breakpoint at $x=c$. Since there are no systematic 
differences between the individuals in all aspects around $x=c$, the reason of the conditional expectation function $E\left(y_{i} \mid x\right)$ jumping here can only be the treatment effect of $D_{i}$. This jump can be regarded as a causal effect on $D_{i}$ at $x=c$.

Since there was a clear dividing line between the lockdown period and the non-lockdown period, namely there were no systematic differences in the weather conditions on either side of the boundary, the only difference was lockdown implementation. Therefore, the days before and after the lockdown were considered local randomization, thus RDD can be used to identify the causal relationship between the lockdown and the air quality.

$$
\ln y_{i}=\alpha+\delta D_{i}+\gamma_{1}\left(x_{i}-c\right)+\gamma_{2} D_{i}\left(x_{i}-c\right)+\varepsilon_{i}, i=1, \ldots, n
$$

where $c$ was the day of the lockdown, and $D_{i}$ (lockdown period above) defined the dummy variable for the implementation of the lockdown policy; when $x_{i} \geq c, D_{i}=0$; when $x_{i}<c, D_{i}=1$; $\delta$ was the air quality jump amplitude measure at the breakpoint.

\section{Results}

\subsection{Air pollution modification under traffic and production restriction}

\subsubsection{Comparisons of air pollution modifications during the same study periods from 2017 to} 2020

Fig. 3 presents the daily concentrations of six air pollutants from January 1st to April 7th over the last four years. As shown in Fig. 3, the concentrations of $\mathrm{PM}_{2.5}, \mathrm{PM}_{10}$ and $\mathrm{NO}_{2}$ decreased notably after the lockdown was implemented in Wuhan (January 23rd), and declined sharply again after February 10th when the residential communities were on lockdown. Because of the restrictions on traffic and production implemented in lockdown, the concentrations of $\mathrm{PM}_{2.5}, \mathrm{PM}_{10}$ and $\mathrm{NO}_{2}$ were significantly lower than those in the same periods over the past three years (20172019), while the concentrations of $\mathrm{O}_{3}, \mathrm{SO}_{2}$ and $\mathrm{CO}$ do not have apparent modification trends. 


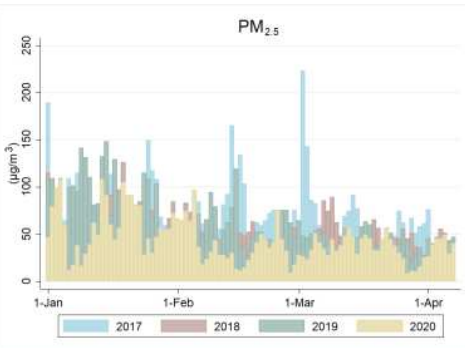

$\mathrm{SO}_{2}$

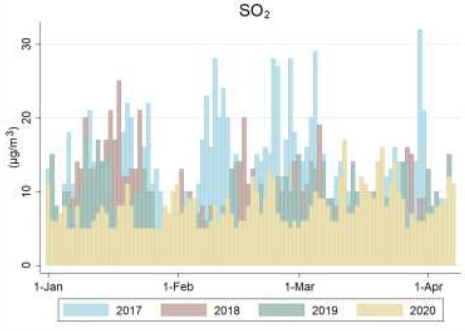

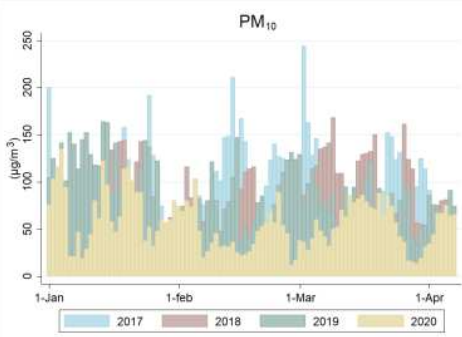

CO

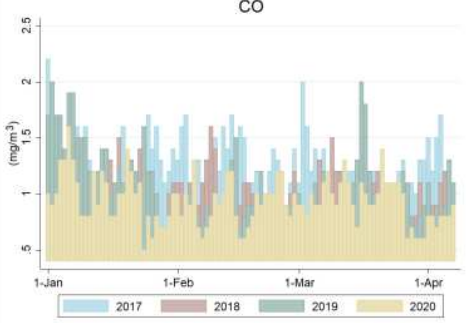

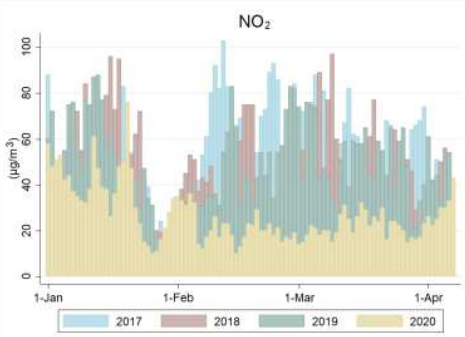

$\mathrm{O}_{3}$

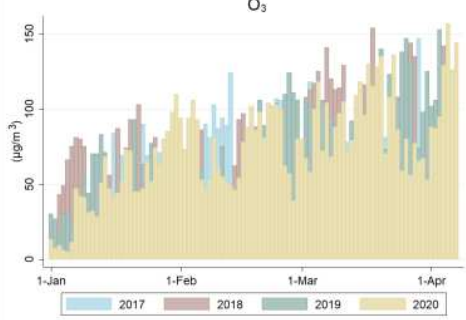

In order to further verify the above findings obtained from descriptive statistics results, the air pollution modifications during the same study periods from 2017 to 2020 are compared using K-W and K-S methods, and the results are shown in Table 2. For each air pollutant, K-W test was used to verify if apparent difference existed in its concentrations during the research period (January 1st - April 7th) over the past four years (2017-2020). The results of K-W test indicated that only the result of $\mathrm{O}_{3}$ failed to reject the null hypothesis, which revealed that the concentration of $\mathrm{O}_{3}$ for the past four years has no apparent difference, i.e., the concentration of $\mathrm{O}_{3}$ has not been affected by the lockdown. The results also illustrated that the results of $\mathrm{PM}_{2.5}, \mathrm{PM}_{10}, \mathrm{NO}_{2}, \mathrm{SO}_{2}$ and CO successfully rejected the null hypothesis, indicating that there is at least one year when each above air pollutant's concentration is different from that in other years. Therefore, it is necessary to detect in which year when the air pollutant's concentration is different. It is easy to understand that if one air pollutant concentration during the research period in 2020 is different from all that in 2019, 2018 and 2017, (i.e., all the results of paired difference tests of 2020 vs. 2019, 2020 vs. 2018 and 2020 vs. 2017 reject the null hypothesis), we can conclude that this air pollutant was significantly affected by the lockdown. If one of the above three paired difference tests can not reject the null hypothesis, then the conclusion that the air pollutant was remarkably affected by the lockdown cannot be deduced. For each air pollutant, the results of paired difference tests of 2020 vs. 2019, 2020 vs. 2018 and 2020 vs. 2017 are listed in Table 2. The results of all the three paired difference tests (i.e., 2020 vs. 2019, 2020 vs. 2018 and 2020 vs. 2017) for $\mathrm{PM}_{2.5}, \mathrm{PM}_{10}$ and $\mathrm{NO}_{2}$ rejected the null hypothesis, which means that the concentrations of $\mathrm{PM}_{2.5}, \mathrm{PM}_{10}$ and $\mathrm{NO}_{2}$ were significantly affected by the lockdown. However, there is no concrete evidence to conclude that the concentrations of $\mathrm{SO}_{2}$ and $\mathrm{CO}$ were affected by the lockdown, because there is one paired 

difference tests (2020 vs. 2018) cannot reject the null hypothesis for CO.

Table 2 The results of K-W test and K-S test for six air pollutants

\begin{tabular}{|c|c|c|c|c|}
\hline & Paired comparison & Methods & Difference & P-value \\
\hline \multirow[t]{4}{*}{$\mathrm{PM}_{2.5}$} & ALL & K-W test & YES & $<0.01$ \\
\hline & 2020 vs. 2019 & K-S test & YES & $<0.01$ \\
\hline & 2020 vs. 2018 & $\mathrm{~K}-\mathrm{S}$ test & YES & $<0.01$ \\
\hline & 2020 vs. 2017 & K-S test & YES & $<0.01$ \\
\hline \multirow[t]{4}{*}{$\mathrm{PM}_{10}$} & ALL & $\mathrm{K}-\mathrm{W}$ test & YES & $<0.01$ \\
\hline & 2020 vs. 2019 & K-S test & YES & $<0.01$ \\
\hline & 2020 vs. 2018 & $\mathrm{~K}-\mathrm{S}$ test & YES & $<0.01$ \\
\hline & 2020 vs. 2017 & K-S test & YES & $<0.01$ \\
\hline \multirow[t]{4}{*}{$\mathrm{SO}_{2}$} & ALL & $\mathrm{K}-\mathrm{W}$ test & YES & $<0.01$ \\
\hline & 2020 vs. 2019 & $\mathrm{~K}-\mathrm{S}$ test & YES & $<0.05$ \\
\hline & 2020 vs. 2018 & K-S test & NO & 0.11 \\
\hline & 2020 vs. 2017 & $\mathrm{~K}-\mathrm{S}$ test & YES & $<0.01$ \\
\hline \multirow[t]{4}{*}{$\mathrm{NO}_{2}$} & ALL & $\mathrm{K}-\mathrm{W}$ test & YES & $<0.01$ \\
\hline & 2020 vs. 2019 & K-S test & YES & $<0.01$ \\
\hline & 2020 vs. 2018 & $\mathrm{~K}-\mathrm{S}$ test & YES & $<0.01$ \\
\hline & 2020 vs. 2017 & K-S test & YES & $<0.01$ \\
\hline \multirow[t]{4}{*}{$\mathrm{CO}$} & ALL & $\mathrm{K}-\mathrm{W}$ test & YES & $<0.01$ \\
\hline & 2020 vs. 2019 & $\mathrm{~K}-\mathrm{S}$ test & NO & 0.15 \\
\hline & 2020 vs. 2018 & K-S test & NO & 0.80 \\
\hline & 2020 vs. 2017 & K-S test & YES & $<0.01$ \\
\hline \multirow[t]{4}{*}{$\mathrm{O}_{3}$} & ALL & $\mathrm{K}-\mathrm{W}$ test & NO & 0.26 \\
\hline & 2020 vs. 2019 & $\mathrm{~K}-\mathrm{S}$ test & NO & 0.07 \\
\hline & 2020 vs. 2018 & $\mathrm{~K}-\mathrm{S}$ test & NO & 0.96 \\
\hline & 2020 vs. 2017 & K-S test & NO & 0.46 \\
\hline
\end{tabular}

\subsubsection{Air pollution modification in different lockdown periods}

The descriptive statistics results for six air pollutants during pre-lockdown, level-I, level-II and level-III periods are shown in Table 3. The paired t-test has been conducted for each air pollutant during each of the four lockdown periods, and the results are shown in Fig. 4 and Table 4. The detailed modifications of each air pollutant during different lockdown periods are presented as follows.

(1) Modification of $\mathrm{PM}_{2.5}$ and $\mathrm{PM}_{10}$ concentrations

According to Table 3, $\mathrm{PM}_{2.5}$ and $\mathrm{PM}_{10}$ concentrations have the similar modification trend in lockdown periods. Their concentrations continuously decreased in all the three lockdown periods, and have largest decline degree in level-III compared with that in pre-lockdown period. Based on 
the results shown in Fig. 4, the $\mathrm{PM}_{2.5}$ and $\mathrm{PM}_{10}$ concentrations in level-I of 2020 have no significant difference with that in other years, while have significant difference in level-II with that in other years. The main reason may be that the lockdown is estimated to show a lag time of about two weeks before causing more complete effects on air pollution. During the level-III, the $\mathrm{PM}_{2.5}$ concentration nearly returned to the average level in previous years because of resumption of production and public transportation. However, the concentration of $\mathrm{PM}_{10}$ did not increase apparently with resumption in level-III, the reason may be that even though the traffic and some important industries resumed, the main emission sources of $\mathrm{PM}_{10}$ such as construction and building material industries were still under restriction because of labor and raw material availability, therefore, the $\mathrm{PM}_{10}$ concentration was still in a low level compared to previous years.

Table 3 Descriptive statistics for air pollutants during different lockdown periods in 2020

\begin{tabular}{|c|c|c|c|c|c|}
\hline Air pollutant & Mean & Std Dev. & Max & Min & Number \\
\hline \multicolumn{6}{|c|}{ Pre-lockdown } \\
\hline $\mathrm{PM}_{2.5}$ & 62.73 & 31.05 & 108 & 12 & 22 \\
\hline $\mathrm{PM}_{10}$ & 75.14 & 36.16 & 105 & 19 & 22 \\
\hline $\mathrm{SO}_{2}$ & 6.77 & 1.85 & 11 & 5 & 22 \\
\hline $\mathrm{NO}_{2}$ & 44.05 & 11.56 & 76 & 26 & 22 \\
\hline $\mathrm{CO}$ & 1.07 & 0.22 & 1.6 & 0.8 & 22 \\
\hline $\mathrm{O}_{3}$ & 36.82 & 21.16 & 73 & 5 & 22 \\
\hline \multicolumn{6}{|c|}{ level-I } \\
\hline $\mathrm{PM}_{2.5}$ & 48.27 & 21.60 & 97 & 18 & 22 \\
\hline $\mathrm{PM}_{10}$ & 53.73 & 22.70 & 103 & 20 & 22 \\
\hline $\mathrm{SO}_{2}$ & 6.82 & 1.92 & 11 & 5 & 22 \\
\hline $\mathrm{NO}_{2}$ & 22.27 & 8.49 & 36 & 10 & 22 \\
\hline $\mathrm{CO}$ & 0.86 & 0.20 & 1.3 & 0.5 & 22 \\
\hline $\mathrm{O}_{3}$ & 71.95 & 20.61 & 110 & 46 & 22 \\
\hline \multicolumn{6}{|c|}{ level-II } \\
\hline $\mathrm{PM}_{2.5}$ & 35.25 & 13.88 & 75 & 9 & 36 \\
\hline $\mathrm{PM}_{10}$ & 51.86 & 22.19 & 89 & 12 & 36 \\
\hline $\mathrm{SO}_{2}$ & 8.47 & 2.88 & 17 & 5 & 36 \\
\hline $\mathrm{NO}_{2}$ & 20.67 & 5.12 & 32 & 10 & 36 \\
\hline $\mathrm{CO}$ & 0.95 & 0.17 & 1.3 & 0.6 & 36 \\
\hline $\mathrm{O}_{3}$ & 89.39 & 23.89 & 135 & 39 & 36 \\
\hline \multicolumn{6}{|c|}{ level-III } \\
\hline $\mathrm{PM}_{2.5}$ & 32.17 & 14.66 & 57 & 8 & 18 \\
\hline $\mathrm{PM}_{10}$ & 48.33 & 23.44 & 86 & 13 & 18 \\
\hline $\mathrm{SO}_{2}$ & 8.89 & 2.97 & 16 & 5 & 18 \\
\hline $\mathrm{NO}_{2}$ & 24.06 & 7.22 & 43 & 15 & 18 \\
\hline $\mathrm{CO}$ & 0.86 & 0.23 & 1.4 & 0.6 & 18 \\
\hline $\mathrm{O}_{3}$ & 93.5 & 32.36 & 157 & 53 & 18 \\
\hline
\end{tabular}



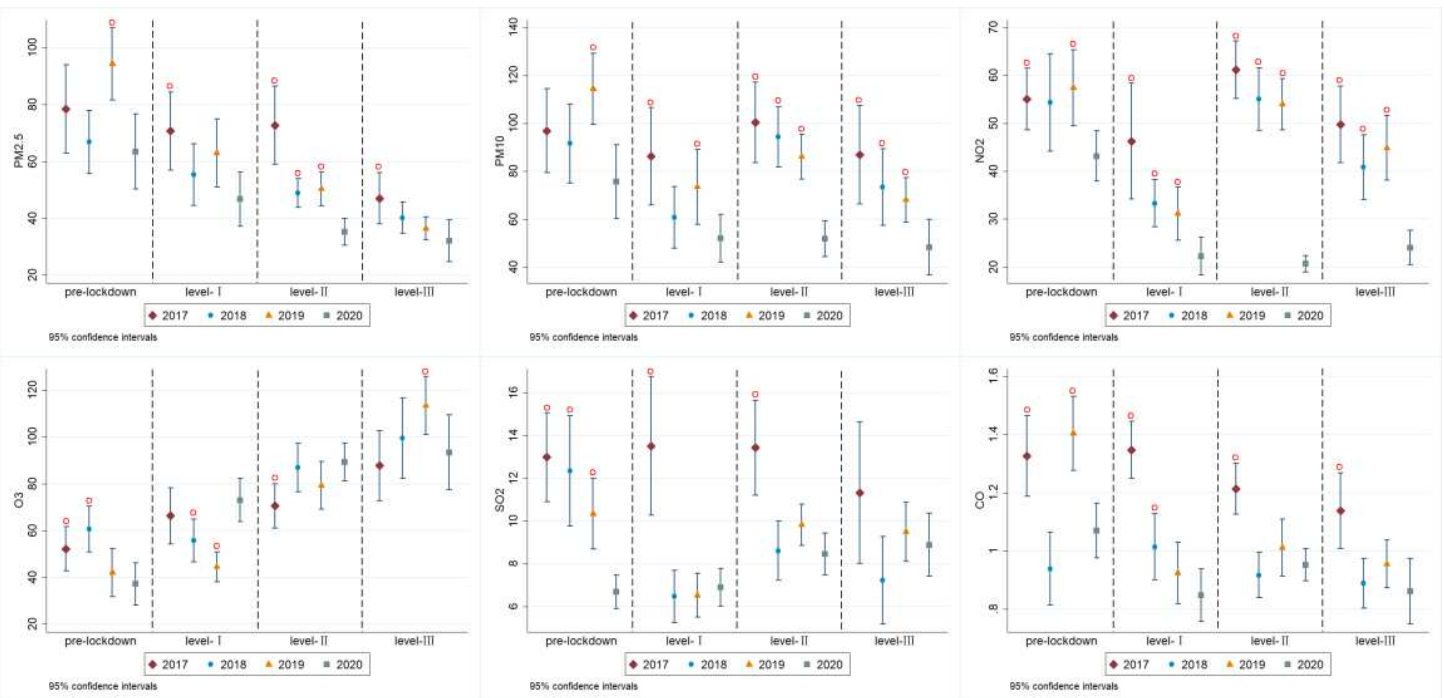

Fig. 4. The results of paired t-test for six air pollutants

Note: the red circle indicates $\mathrm{P}<0.05$

(2) Modification of $\mathrm{NO}_{2}$ concentration

As shown in Fig. 4, the concentration of $\mathrm{NO}_{2}$ has a rapid decreasing trend as soon as the lockdown is implemented in the level-I period, and kept in a low level in the level-II, while has a quick increase once the lockdown eased in level-III. The rapid response of $\mathrm{NO}_{2}$ concentration to lockdown indicates that the link between them is tight and apparent. Moreover, During the lockdown period, the reduction of $\mathrm{NO}_{2}$ concentration was the largest among all the six air pollutants (see Table 4). It has been confirmed by many previous researches that almost all $\mathrm{NO}_{2}$ derives directly from the exhaust emission. Therefore, once the traffic restriction was implemented, the $\mathrm{NO}_{2}$ concentration sharply declined without any lag time, oppositely, once the traffic restriction eased, the $\mathrm{NO}_{2}$ concentration rapidly increase without any delay. These findings remind us that the exhaust emission reduction policies such as promoting electric vehicles, private vehicle transport reduction and encouraging public transport can effectively reduce the $\mathrm{NO}_{2}$ concentration.

(3) Modification of $\mathrm{O}_{3}, \mathrm{SO}_{2}$ and $\mathrm{CO}$ concentrations

Among six air pollutants, $\mathrm{O}_{3}$ was the only pollutant with upward trend during the lockdown period, and this increasing trend also existed in the same periods of the previous three years from 2017 to 2019. As shown in Fig. 4, the mean values of $\mathrm{SO}_{2}$ and $\mathrm{CO}$ have no apparent modification trend during the lockdown period. During the whole lockdown period, $\mathrm{SO}_{2}$ and $\mathrm{CO}$ concentrations in 2020 were not significantly different from that in the past three years, indicating that $\mathrm{SO}_{2}$ and $\mathrm{CO}$ concentrations were barely affected by the lockdown. The reason may lie in the following two 
aspects: (1) in fact, in the lockdown, even though the traffic and production are restricted strictly, in order to keep the normal life of citizens, most of the heating and electricity generation industries which are the main sources of $\mathrm{SO}_{2}$ and $\mathrm{CO}$ were not affected; (2) moreover, because of residential lockdown, the time of household stove usage and heating was remarkably extended.

Table 4 The change values of six air pollutants' concentrations during different lockdown periods compared to that in previous three years

\begin{tabular}{|c|c|c|c|}
\hline & $\begin{array}{l}\text { Difference between } 2020 \\
\text { and } 2017 \text { (\% change) }\end{array}$ & $\begin{array}{l}\text { Difference between } 2020 \\
\text { and } 2018 \text { (\% change) }\end{array}$ & $\begin{array}{l}\text { Difference between } 2020 \\
\text { and } 2019 \text { (\% change) }\end{array}$ \\
\hline \multicolumn{4}{|c|}{$\mathrm{PM}_{2.5}$} \\
\hline pre-lockdown & $-15.09(19.21 \%)$ & $-3.39(5.07 \%)$ & $-30.91(29.57 \%)$ \\
\hline level-I & $-29.10(38.36 \%)$ & $-8.67(15.64 \%)$ & $-16.29(25.84 \%)$ \\
\hline level-II & $-37.53(51.57 \%)$ & $-13.69(27.97 \%)$ & $-15.14(30.05 \%)$ \\
\hline level-III & $-14.89(31.64 \%)$ & $-8.11(20.13 \%)$ & $-4.33(11.86 \%)$ \\
\hline \multicolumn{4}{|c|}{$\mathrm{PM}_{10}$} \\
\hline pre-lockdown & $-21.17(21.85 \%)$ & $-15.87(17.32 \%)$ & $-38.65(33.79 \%)$ \\
\hline level-I & $-40.67(43.87 \%)$ & $-8.81(14.48 \%)$ & $-21.47(29.20 \%)$ \\
\hline level-II & $-48.50(48.33 \%)$ & $-42.53(45.06 \%)$ & $-34.31(39.82 \%)$ \\
\hline level-III & $-38.61(44.41 \%)$ & $-25.11(34.19 \%)$ & $-19.78(29.04 \%)$ \\
\hline \multicolumn{4}{|c|}{$\mathrm{SO}_{2}$} \\
\hline pre-lockdown & $-6.30(48.46 \%)$ & $-5.65(45.75 \%)$ & $-3.65(35.27 \%)$ \\
\hline level-I & $-6.62(48.96 \%)$ & $0.43(6.64 \%)$ & $0.38(5.83 \%)$ \\
\hline level-II & $-4.97(36.98 \%)$ & $-0.14(1.63 \%)$ & $-1.36(13.84 \%)$ \\
\hline level-III & $-2.44(21.54 \%)$ & $1.67(23.13 \%)$ & $-0.61(6.42 \%)$ \\
\hline \multicolumn{4}{|c|}{$\mathrm{CO}$} \\
\hline pre-lockdown & $-0.26(29.55 \%)$ & $0.13(13.83 \%)$ & $-0.33(23.57 \%)$ \\
\hline level-I & $-0.50(37.04 \%)$ & $-0.17(16.83 \%)$ & $-0.07(7.61 \%)$ \\
\hline level-II & $-0.26(21.49 \%)$ & $0.04(4.35 \%)$ & $-0.06(5.94 \%)$ \\
\hline level-III & $-0.28(24.56 \%)$ & $-0.28(31.46 \%)$ & $-0.09(9.38 \%)$ \\
\hline \multicolumn{4}{|c|}{$\mathrm{NO}_{2}$} \\
\hline pre-lockdown & $-11.91(21.64 \%)$ & $-11.22(20.64 \%)$ & $-14.3(24.90 \%)$ \\
\hline level-I & $-24.05(51.96 \%)$ & $-11.05(33.19 \%)$ & $-8.90(28.58 \%)$ \\
\hline level-II & $-40.53(66.24 \%)$ & $-34.39(62.46 \%)$ & $-33.33(61.72 \%)$ \\
\hline level-III & $-25.72(51.67 \%)$ & $-16.78(41.10 \%)$ & $-20.83(46.40 \%)$ \\
\hline
\end{tabular}


$\mathrm{O}_{3}$

\begin{tabular}{lrrr} 
pre-lockdown & $-15.00(28.70 \%)$ & $-23.43(38.6 \%)$ & $-4.87(13.07 \%)$ \\
level-I & $6.76(10.18 \%)$ & $17.29(30.95 \%)$ & $28.52(63.92 \%)$ \\
level-II & $18.75(26.54 \%)$ & $2.25(2.58 \%)$ & $9.97(12.55 \%)$ \\
level-III & $5.67(6.46 \%)$ & $-6.22(6.24 \%)$ & $-20.00(17.62 \%)$ \\
\hline
\end{tabular}

\subsection{Structural break points in six air pollutants}

\subsubsection{Regression Discontinuity Design results}

In this section, the structural break points in six air pollutants during the lockdown period were detected using RDD. After implementation of lockdown, the concentrations of $\mathrm{PM}_{2.5}, \mathrm{PM}_{10}, \mathrm{NO}_{2}$ and $\mathrm{CO}$ declined considerably because of restrictions on production and traffic (see Fig. 5). Table 5 shows that there were structural break points in $\mathrm{PM}_{2.5}, \mathrm{PM}_{10}, \mathrm{NO}_{2}$ and $\mathrm{CO}$, but no structural break points in $\mathrm{SO}_{2}$ and $\mathrm{O}_{3}$. With comparison of the RDD coefficients of $\mathrm{PM}_{2.5}$ (-34.46), $\mathrm{PM}_{10}$ $(-37.11)$ and $\mathrm{NO}_{2}(-19.15)$, the coefficient of $\mathrm{CO}(-0.32)$ indicates that the traffic and production restriction has less influence on $\mathrm{CO}$ concentration compared to that on $\mathrm{PM}_{2.5}, \mathrm{PM}_{10}, \mathrm{NO}_{2}$ concentrations. In summary, it can be seen that the lockdown has significant effect on $\mathrm{PM}_{2.5}, \mathrm{PM}_{10}$, $\mathrm{NO}_{2}$ concentrations, less influences on $\mathrm{CO}$, and no influences on $\mathrm{SO}_{2}$ and $\mathrm{O}_{3}$.
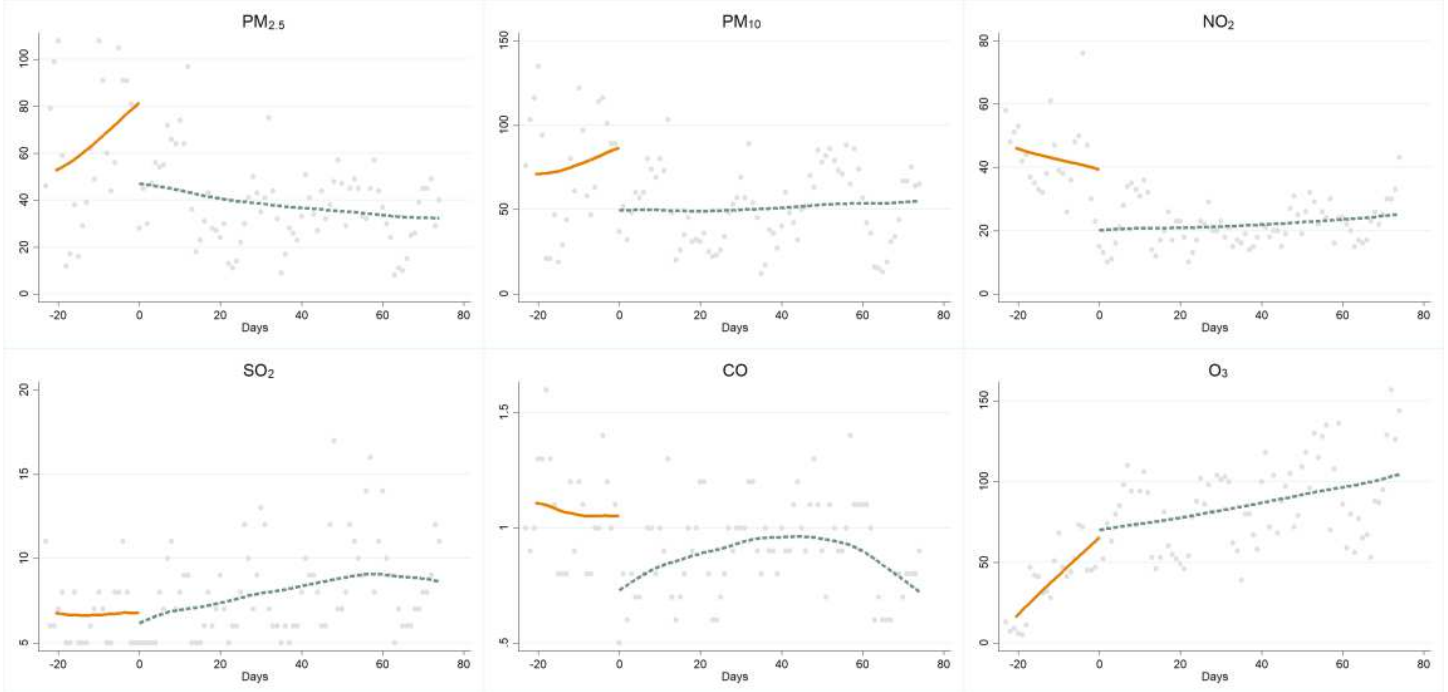

Fig. 5. RDD results for six air pollutants, 2020

Table 5 Estimation results for RDD

\begin{tabular}{lllllll}
\hline & $\mathrm{PM}_{2.5}$ & $\mathrm{PM}_{10}$ & $\mathrm{SO}_{2}$ & $\mathrm{CO}$ & $\mathrm{NO}_{2}$ & $\mathrm{O}_{3}$ \\
\hline 2020 & $-34.46^{* * *}$ & $-37.11^{* * *}$ & -0.62 & $-0.32^{* * *}$ & $-19.15^{* * *}$ & 4.81 \\
\hline
\end{tabular}




\begin{tabular}{lllllll}
\hline 2019 & -6.27 & -10.44 & -2.89 & 0.03 & $-11.42^{*}$ & $-22.68^{* *}$ \\
\hline
\end{tabular}

Note: ${ }^{*} \mathrm{p}<.10,{ }^{* *} \mathrm{p}<.05,{ }^{* * *} \mathrm{p}<.01$

\subsubsection{Spring Festival effect on air pollution}

Because the Spring Festival overlapped with the COVD-19 in the year 2020, ignoring the Spring

Festival effect may reduce the reliability of the results. In this section, the Spring Festival effect on the air pollution is investigated based on RDD model through comparing the sharp changes in air pollutants during the year 2019 and 2020, the results indicated that there are no any sharp changes in the air pollutants in 2019 during the Spring Festival (see Fig. 6), thus we can deduce that the sharp changes in the air pollutants in 2020 are unlikely to be caused by the Spring Festival.
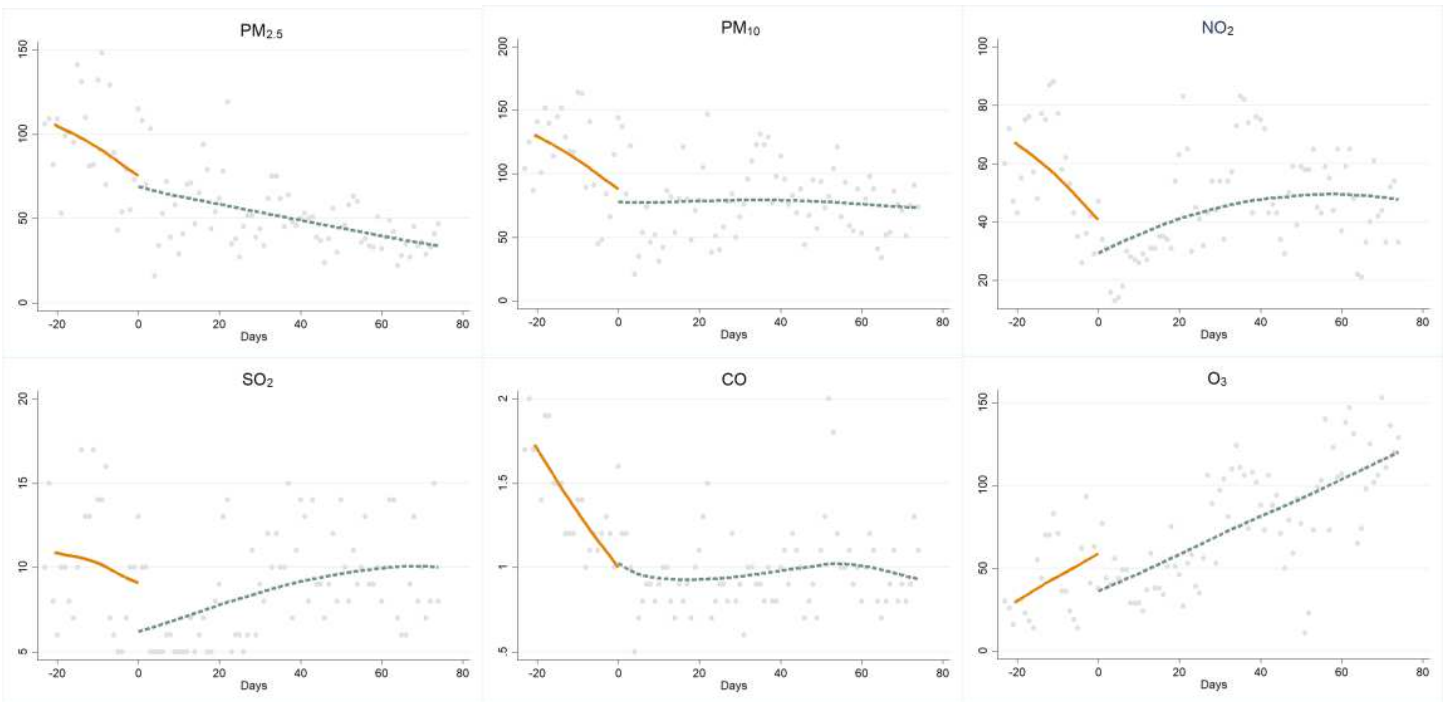

Fig. 6. RDD results for six air pollutants, 2019

\subsubsection{Bandwidth sensitivity analysis}

Since the bandwidth size could significantly affect the RDD results, to ensure regression robustness, 3-6 days before and after the implementation of the lockdown policy were used as the bandwidth for RDD. Table 6 shows the estimates and significance of the coefficients for different bandwidths. Since there were no significant structural changes in $\mathrm{SO}_{2}$ and $\mathrm{O}_{3}$, these two air pollutants were excluded from the scope of bandwidth sensitivity analysis. Under the different bandwidths, the coefficients of $\mathrm{PM}_{2.5}, \mathrm{PM}_{10}, \mathrm{CO}$ and $\mathrm{NO}_{2}$ are all significantly negative, which was consistent with the results in section 3.2.1. Therefore, the bandwidth sensitivity analysis revealed that the lockdown had a relatively stable impact on the air pollutants' concentrations and the choice of different bandwidths did not affect the core conclusions of this research. 


\begin{tabular}{lllll}
\hline & $\mathrm{PM}_{2.5}$ & $\mathrm{PM}_{10}$ & $\mathrm{CO}$ & $\mathrm{NO}_{2}$ \\
\hline 3 days & $-31.21^{* * *}$ & -33.20 & $-0.55^{* * *}$ & $-18.78^{* *}$ \\
4 days & $-30.76^{* * *}$ & $-32.09^{* * *}$ & $-0.48^{* * *}$ & $-18.22^{* *}$ \\
5 days & $-32.65^{* * *}$ & $-34.70^{* * * *}$ & $-0.40^{* * *}$ & $-18.59^{* *}$ \\
6 days & $-33.95^{* * *}$ & $-37.25^{* * *}$ & $-0.35^{* * *}$ & $-18.91^{* * *}$ \\
\hline
\end{tabular}

Note: ${ }^{*} \mathrm{p}<.10,{ }^{* *} \mathrm{p}<.05,{ }^{* * *} \mathrm{p}<.01$

\section{Discussions}

\subsection{Equivalence between the lockdown and restriction on traffic \& production}

The purpose of this study is to investigate the effects of traffic and production restriction on air pollution at a city level, however, these two measures have never been implemented in a large area like a city for long enough period of time, so the effectiveness of these two measures have never been estimated quantitatively at a city level. The COVID-19 occurred in 2019 caused a large scale and long-term lockdown in Wuhan, and the restrictions on traffic and production in lockdown can be regarded as a natural experimental condition. Fig. 2 presented the implementation periods of detailed restrictions on traffic and production, after implementation of these restriction policies, the traffic and production in Wuhan have been extensively limited. Compared to 2019, the monthly bus passenger volume and taxi passenger volume in 2020 decreased by $99.26 \%$ and $98.68 \%$ in February, $98.52 \%$ and $98.10 \%$ in March, respectively (see Fig. 7 (a)-(b)). According to the data released by Wuhan Bureau of Statistics, in the first quarter of 2020 the Wuhan's GDP sharply declined by $40.5 \%$ and the secondary industry dropped by $45.4 \%$ in comparison with the same period in 2019 (Fig. 7 (c)).
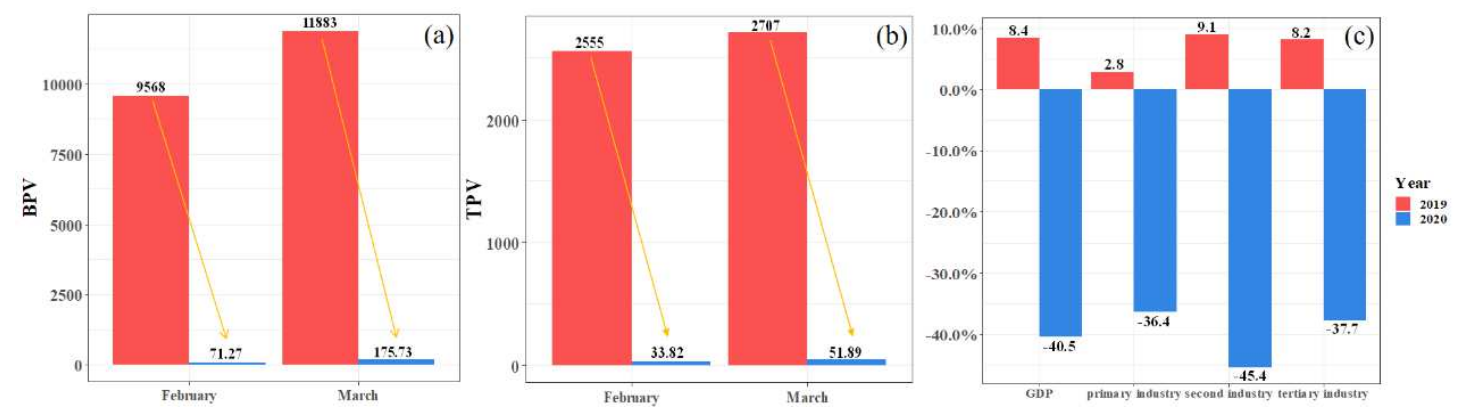

Fig. 7. Monthly variation of (a) Bus Passenger Volume (BPV), (b) Taxi Passenger Volume (TPV), and (c) annual variation of output value in the first quarter

Based on the above consideration, the lockdown can be regarded as a natural experiment condition for analyzing the effects of traffic and production restriction on the air pollution. Moreover, as a typical industrial and resource-based city, Wuhan has suffered from heavy air 
pollution containing aerosol particles $\left(\mathrm{PM}_{2.5}, \mathrm{PM}_{10}\right)$ and gaseous pollutants $\left(\mathrm{NO}_{\mathrm{X}}, \mathrm{SO}_{2}, \mathrm{O}_{3}, \mathrm{CO}\right)$ for many years. Therefore, it is feasible to conduct this study based on the data collected during the lockdown period in Wuhan.

\subsection{The reliability and validity of the results}

(1) Similarities with previous studies

Collivignarelli et al. (2021) found the $\mathrm{NO}_{2}$ concentrations in London, Milan and Paris under the travel restrictions decreased by $80.8 \%, 42.4 \%$ and $79.8 \%$, respectively. Ju et al. (2021) obtained the conclusion that $\mathrm{PM}_{2.5}$ and $\mathrm{PM}_{10}$ concentrations in Korea decreased significantly during the COVID-19 period under the traffic and production restrictions. All the above studies show that there are strong correlations between the restriction on traffic and production and the concentrations of $\mathrm{PM}_{2.5}, \mathrm{PM}_{10}$ and $\mathrm{NO}_{2}$, which is consistent with the findings obtained in this study. Lian et al. (2020) found that the $\mathrm{SO}_{2}$ concentration in Wuhan, China was not affected apparently by the lockdown, which is similar to the result found in this study.

(2) Differences with previous studies

Because the study area and period in this research were different from that in previous studies, this study also obtained some new findings which mainly includes the following two aspects.

(a) Tobias et al. (2020) found the $\mathrm{O}_{3}$ concentration has an increasing trend during the lockdown period and deduced that the increasing trend of $\mathrm{O}_{3}$ concentration was caused by the sharply decline of $\mathrm{NO}_{2}$ concentration. Inconsistent to findings in Tobias et al. (2020), although this study also obtained the increasing trend of $\mathrm{O}_{3}$ concentration during lockdown period, after comparing with changing trend of $\mathrm{O}_{3}$ concentration in the past four years from 2017 to 2020 , this study found that its increase was not limited to the lockdown period, i.e., the $\mathrm{O}_{3}$ concentration presented the steady increase trend in the same periods for the past four years. Therefore, it can be concluded that the $\mathrm{O}_{3}$ increase in the current study is unlikely to be attributable to the reduced production and traffic during the lockdown in Wuhan.

(b) Liu et al. (2021) found the CO concentration has a notably decreasing trend under the traffic and production restriction during the lockdown period, which indicates that the traffic and production restriction can affect the level of $\mathrm{CO}$ concentration. This study also found the decreasing trend of $\mathrm{CO}$ concentration in the lockdown, however, with comparison of the RDD estimated coefficient of $\mathrm{PM}_{2.5}$ (-34.46), $\mathrm{PM}_{10}$ (-37.11), $\mathrm{NO}_{2}$ (-19.15), the RDD estimated coefficient of $\mathrm{CO}(-0.32)$ indicates that the traffic and production restriction has less influence on $\mathrm{CO}$ concentration compared to that on $\mathrm{PM}_{2.5}, \mathrm{PM}_{10}, \mathrm{NO}_{2}$. 


\subsection{Effectiveness and limitation of traffic and production restriction}

As the widely used measures for controlling the heavy air pollution, the traffic and production restriction have been verified in this study to be effective for reducing the $\mathrm{PM}_{2.5}, \mathrm{PM}_{10}$ and $\mathrm{NO}_{2}$ concentrations. However, the traffic and production restriction has nearly no effect on $\mathrm{SO}_{2}$ and $\mathrm{O}_{3}$, in which $\mathrm{O}_{3}$ has become the primary air pollutant in many places in China for several years (Wang et al., 2021a). Although the results of this study presented correlation between CO concentration and restriction on traffic and production, the traffic and production restriction has less influence on $\mathrm{CO}$ concentration compared to $\mathrm{PM}_{2.5}, \mathrm{PM}_{10}$ and $\mathrm{NO}_{2}$. Therefore, in order to control the air pollution, the traffic and production restriction policy is not enough, more comprehensive measures should be adopted to control $\mathrm{SO}_{2}, \mathrm{O}_{3}$ and $\mathrm{CO}$ concentrations.

\subsection{Spring Festival effect on air pollution during lockdown}

Wang et al. (2021b) found that the air pollution level can be affected apparently by the Spring Festival, this can be interpreted by the production reduction and traffic increase. However, through comparing the sharp changes in air pollutants in the year 2019 and 2020, it can be found that there are no any sharp changes in the air pollutants in 2019 during the Spring Festival. Therefore, it can be deduced that the sharp changes in the air pollutants in 2020 are unlikely to be caused by the Spring Festival.

\section{Conclusions}

Traffic and production restrictions are two widely used measures for controlling the heavy air pollution. However, these two measures are often applied in a small area for a short time in order to reduce the negative influences on human activities, therefore, the effectiveness of these two measures have not been scientifically verified through a city-level empirical study, which leads to the lack of implementation basis of these two measures. This study, adopted Wuhan as the study area, firstly verifies the existence of lockdown effect on air pollution and analyzes the change rule of six air pollutants $\left(\mathrm{PM}_{2.5}, \mathrm{PM}_{10}, \mathrm{NO}_{2}, \mathrm{SO}_{2}, \mathrm{CO}\right.$ and $\left.\mathrm{O}_{3}\right)$ in different lockdown periods using $\mathrm{K}-\mathrm{W}$, $\mathrm{K}-\mathrm{S}$ and paired t-test methods. Then the structural break points in six air pollutants and the Spring Festival effect are investigated with RDD model.

The following six conclusions are obtained.

(1) Compared to the past three years from 2017 to 2019, the $\mathrm{PM}_{2.5}, \mathrm{PM}_{10}$ and $\mathrm{NO}_{2}$ concentrations declined sharply in lockdown period, indicating that the traffic and production restriction has apparently effects on these above three air pollutants' concentrations; (2) Compared to the past three years from 2017 to 2019, the CO concentration also has a decreasing trend in 
lockdown, however, according to the RDD estimated coefficients of different air pollutants, it is

413 found that the traffic and production restriction has less influence on CO concentration compared 414 to that on $\mathrm{PM}_{2.5}, \mathrm{PM}_{10}$ and $\mathrm{NO}_{2}$; (3) This study obtained the increasing trend of $\mathrm{O}_{3}$ concentration 415 during lockdown period, after comparing with the changing trend of $\mathrm{O}_{3}$ concentration in the past 416 four years from 2017 to 2020 , this study found that its increase was not limited to the lockdown 417 period, i.e., the $\mathrm{O}_{3}$ concentrations have presented the steady increase trend in the same periods over the past four years. Therefore, it can be concluded that the increase in $\mathrm{O}_{3}$ in the current study is unlikely to be attributed to the reduced production and traffic during the lockdown in Wuhan; (4) Compared to the past three years from 2017 to 2019, the $\mathrm{SO}_{2}$ concentration has no apparent modification trend during the lockdown, indicating that the traffic and production restriction has no effect on $\mathrm{SO}_{2}$ concentration; (5) The air pollution level can be affected apparently by the Spring Festival, but the sharp changes in the air pollutants in 2020 are unlikely to be caused by the Spring Festival; (6) The concentrations of $\mathrm{PM}_{2.5}$ and $\mathrm{PM}_{10}$ started to decline in the Level-II period during lockdown, while the concentration of $\mathrm{NO}_{2}$ has a rapid decreasing trend as soon as the traffic and production restriction is implemented in the Level-I period, indicating that there is an lagged effect on the influences of traffic and production restriction on the $\mathrm{PM}_{2.5}$ and $\mathrm{PM}_{10}$; (7) Traffic and production restriction policy is effective for controlling the $\mathrm{PM}_{2.5}, \mathrm{PM}_{10}$ and $\mathrm{NO}_{2}$, less effective for $\mathrm{CO}$, and ineffective for $\mathrm{SO}_{2}$ and $\mathrm{O}_{3}$.

In summary, in order to control the air pollution, the traffic and production restriction policy is not enough, and more comprehensive measures should be adopted to control $\mathrm{SO}_{2}, \mathrm{O}_{3}$ and $\mathrm{CO}$

Authors contribution Yiqing Chen collected the data and conducted the experiments. Deyun Wang designed the experiments and analyzed the results. Adnen Elamraoui and Haixiang Guo provided critical review and manuscript editing. Yiqing Chen and Deyun Wang wrote the paper. All authors read and approved the final manuscript.

Data availability The data that support the findings of this study are available from the corresponding author or the http://www.aqistudy.cn upon reasonable request.

Funding This research was funded by the Hubei Provincial Natural Science Foundation of China 


\section{Declarations}

446 Ethics approval and consent to participate Not applicable.

447 Consent for publication Not applicable.

448 Competing interests The authors declare no competing interests.

\section{References}

Al-Qaness, M.A.A., Fan, H., Ewees, A.A., Yousri, D., Abd Elaziz, M., 2020. Improved ANFIS model for

Alahmad, B., Al-Hemoud, A., Kang, C.M., Almarri, F., Kommula, V., Wolfson, J.M., Bernstein, A.S., Garshick, E., Schwartz, J., Koutrakis, P., 2021. A two-year assessment of particulate air pollution and sources in Kuwait. Environmental Pollution. 282, 117016-117025.

Ali, S.M., Malik, F., Anjum, M.S., Siddiqui, G.F., Anwar, M.N., Lam, S.S., Nizami, A.S., Khokhar, M.F., 2021. Exploring the linkage between PM2.5 levels and COVID-19 spread and its implications for socio-economic circles. Environmetal Research. 193, 110421-110429.

Baldasano, J.M., 2020. COVID-19 lockdown effects on air quality by NO2 in the cities of Barcelona and Madrid (Spain). Science of the Total Environment. 741, 140353-140362.

Berman, J.D., Ebisu, K., 2020. Changes in U.S. air pollution during the COVID-19 pandemic. Science of the Total Environment. 739, 139864-139867.

Chauhan, A., Singh, R.P., 2020. Decline in PM2.5 concentrations over major cities around the world associated with COVID-19. Environmental Research. 187, 109634-109637.

Choi, H., Myong, J.P., 2018. Association between air pollution in the 2015 winter in South Korea and population size, car emissions, industrial activity, and fossil-fuel power plants: an ecological study. Annals of Occupational and Environmetal Medicine. 30, 60-66.

Collivignarelli, M.C., De Rose, C., Abba, A., Baldi, M., Bertanza, G., Pedrazzani, R., Sorlini, S., Carneva le Miino, M., 2021. Analysis of lockdown for CoViD-19 impact on NO2 in London, Milan and Pari s: What lesson can be learnt? Process Safety and Environmetal Protection. 146, 952-960.

Danesh Yazdi, M., Wang, Y., Di, Q., Zanobetti, A., Schwartz, J., 2019. Long-term exposure to PM2.5 and ozone and hospital admissions of Medicare participants in the Southeast USA. Environmetal International. 130, 104879-104885.

De La Cruz, A.R.H., Dionisio Calderon, E.R., França, B.B., Réquia, W.J., Gioda, A., 2019. Evaluation of the impact of the Rio 2016 Olympic Games on air quality in the city of Rio de Janeiro, Brazil. Atmospheric Environment. 203, 206-215.

Hao, J., Yang, Z., Huang, S., Yang, W., Zhu, Z., Tian, L., Lu, Y., Xiang, H., Liu, S., 2019. The association between short-term exposure to ambient air pollution and the incidence of mumps in Wuhan, China: A time-series study. Environmetal Research. 177, 108660-108669. 
Hua, J., Zhang, Y., de Foy, B., Mei, X., Shang, J., Feng, C., 2021. Competing PM2.5 and NO2 holiday effects in the Beijing area vary locally due to differences in residential coal burning and traffic patterns. Science of the Total Environment. 750, 141575-141583.

Ju, M.J., Oh, J., Choi, Y.H., 2021. Changes in air pollution levels after COVID-19 outbreak in Korea. Science of the Total Environment. 750, 141521-141529.

Li, L., Li, Q., Huang, L., Wang, Q., Zhu, A., et.al., 2020. Air quality changes during the COVID-19 lockdown over the Yangtze River Delta Region: An insight into the impact of human activity pattern changes on air pollution variation. Science of the Total Environment. 732, 139282-139292.

Lian, X., Huang, J., Huang, R., Liu, C., Wang, L., Zhang, T., 2020. Impact of city lockdown on the air quality of COVID-19-hit of Wuhan city. Science of the Total Environment. 742, 140556-140564.

Liu, Q., Harris, J.T., Chiu, L.S., Sun, D., Houser, P.R., Yu, M., Duffy, D.Q., Little, M.M., Yang, C., 2021. Spatiotemporal impacts of COVID-19 on air pollution in California, USA. Science of the Total Environmet. 750, 141592-141600.

Miao, Z., Baležentis, T., Shao, S., Chang, D., 2019. Energy use, industrial soot and vehicle exhaust pollution-China's regional air pollution recognition, performance decomposition and governance. Energy Economics. 83, 501-514.

Nakada, L.Y.K., Urban, R.C., 2020. COVID-19 pandemic: Impacts on the air quality during the partial lockdown in Sao Paulo state, Brazil. Science of the Total Environment. 730, 139087-139091.

Razzaq, A., Sharif, A., Aziz, N., Irfan, M., Jermsittiparsert, K., 2020. Asymmetric link between environmental pollution and COVID-19 in the top ten affected states of US: A novel estimations from quantile-on-quantile approach. Environment Research. 191, 110189-110198.

Sulaymon, I.D., Zhang, Y., Hopke, P.K., Zhang, Y., Hua, J., Mei, X., 2021. COVID-19 pandemic in Wuhan: Ambient air quality and the relationships between criteria air pollutants and meteorological variables before, during, and after lockdown. Atmospheric Research. 250, 105362-105373.

Talbot, N., Takada, A., Bingham, A.H., Elder, D., Lay Yee, S., Golubiewski, N.E., 2021. An investigation of the impacts of a successful COVID-19 response and meteorology on air quality in New Zealand. Atmospheric Environment. 254, 118322-118335.

Tao, M., Huang, H., Chen, N., Ma, F., Wang, L., Chen, L., Wang, L., Zhang, L., Xiang, J., Kong, H., Gui, L., 2021. Contrasting effects of emission control on air pollution in Central China during the 2019 Military World Games based on satellite and ground observations. Atmospheric Research. 259, 105657-105666.

Tobias, A., Carnerero, C., Reche, C., Massague, J., Via, M., Minguillon, M.C., Alastuey, A., Querol, X., 2020. Changes in air quality during the lockdown in Barcelona (Spain) one month into the SARS-CoV-2 epidemic. Science of the Total Environment. 726, 138540-138543.

Wang, C., Wang, Y., Shi, Z., Sun, J., Gong, K., Li, J., Qin, M., Wei, J., Li, T., Kan, H., Hu, J., 2021a. Effects of using different exposure data to estimate changes in premature mortality attributable to PM2.5 and O3 in China. Environmental Pollution. 285, 117242-117250.

Wang, Z., Uno, I., Yumimoto, K., Itahashi, S., Chen, X., Yang, W., Wang, Z., 2021b. Impacts of COVID-19 lockdown, Spring Festival and meteorology on the NO2 variations in early 2020 over China based on in-situ 

observation of VOCs, NOx, and O3 at an urban site in Wuhan, China. Journal of Environmental Sciences (China). 79, 297-310. Burden of ischemic heart disease and stroke attributable to exposure to atmospheric PM2.5 in Hubei province, China. Atmospheric Environment. 221, 117079-117083.

Yuan, Q., Qi, B., Hu, D., Wang, J., Zhang, J., Yang, H., Zhang, S., Liu, L., Xu, L., Li, W., 2021. Spatiotemporal variations and reduction of air pollutants during the COVID-19 pandemic in a megacity of Yangtze River Delta in China. Science of the Total Environment. 751, 141820-141828. COVID-19 pandemic. Science of the Total Environment. 742, 140496-140501. oxides emission reduction from China due to COVID-19 and its impact on surface ozone and aerosol pollution. Science of the Total Environment. 753, 142238-142244. 